\title{
A historical glimpse into treating childhood hydrocephalus
}

\author{
Amin Demerdash • Rajani Singh • Marios Loukas • \\ R. Shane Tubbs
}

Received: 15 January 2015 / Accepted: 10 February 2015 / Published online: 24 February 2015

(C) Springer-Verlag Berlin Heidelberg 2015

\section{Introduction}

Hydrocephalus was known to the ancients with Hippocrates describing it as early as the fifth century $\mathrm{BC}$; some even claim that he made the first attempt to drain this excess fluid. Hundreds of years later, Galen (130-200 AD) made some of the early contributions to the then-mysterious condition [1]. In the tenth century, Abul-Qasim Al-Zahrawi, who is also known as Abulcasis, wrote a 30 -volume treatise considered by many as a medical encyclopedia; he was the first to give details about the instruments used in decompression-trepanation as a treatment for hydrocephalus [2].

Some rare reports of hydrocephalus and its treatment were seen in the sixteenth century (Fig. 1 and cover figure), but it was not until the seventeenth century when Isbrand de Diemerbroeck presumed that bad nutrition and poor feeding were the main reasons for the enlargement of an 18-month-old child's head; he described it to be "as big as a man's head." His explanation for the swelling was that an unhealthy diet caused the production of copious amounts of phlegm and thick fluids that then traveled from the intestines to the skull. He proposed a simple treatment composed of a laxative syrup and a warm head poultice while giving the child a "dry" diet in an attempt to decrease the amount of fluids in the body, but if these modalities failed, a small skin puncture could be made to evacuate the fluid [3]. Meanwhile, English physician Nicholas Culpeper thought the disease was fatal and very difficult to cure; however, he suggested some basic home preparations

\footnotetext{
A. Demerdash $\cdot$ R. S. Tubbs $(\bowtie)$

Pediatric Neurosurgery, Children's of Alabama, Birmingham, AL, USA

e-mail: shane.tubbs@childrensal.org

R. Singh

Department of Anatomy, AIIMS, Rishikesh, Uttrakhand, India

M. Loukas

Department of Anatomical Sciences, St. George's University, St. George, Grenada
}

to be applied on the head to help decrease the swelling. In 1663 , Robert Bayfield suggested wrapping the head with warm wool and applying an ointment [4].

Less than a hundred years later, French surgeon ClaudeNicolas Le Cat made the first documented attempt of a ventricular puncture for hydrocephalus in 1744 (Fig. 2). Le Cat thought that rapid evacuation of the fluid was the main reason surgical treatments did not work. He reported the case of a 3month-old child with massive head enlargement. Le Cat used his newly invented trocar to slowly drain the fluid outside the brain; however, his patient did not survive a second attempt [5, 6].

Still in the eighteenth century, in his letter to Dr. Hans Sloane, John Friend detailed the results of an autopsy performed on a 2-year-old patient with hydrocephalus. Friend mentioned that there was a lack of fusion of the skull due to the large amounts fluid, which occupied the space between the pia mater and dura mater [7].

Around the same time, another English physician, Michael Underwood, explained the symptoms associated with hydrocephalus which was described by him as a disease that is difficult to diagnose and even more difficult to treat. As described by Underwood, hydrocephalus could begin with vomiting, low-grade fever, photosensitivity, diplopia, and bradycardia. Later in the course of the disease, patients would have dilated pupils and tachycardia before falling into deep coma that would eventually lead to death [4].

The nineteenth century saw a giant leap in the understanding of hydrocephalus with many renowned physicians contributing to the topic (Fig. 3). Starting with Mathew Baillie in the early 1800 s, his work on morbid anatomy had a very detailed description of hydrocephalus [8]. Richard Bright (1789-1858) gave a good example of hydrocephalus by pointing out the case of James Cardinal and used his wonderful hand-colored illustrations to explain the nature of the then fatal disease [9].

In the mid nineteenth century, around the time of the early "resurrectionists," Robert Liston studied hydrocephalus and 


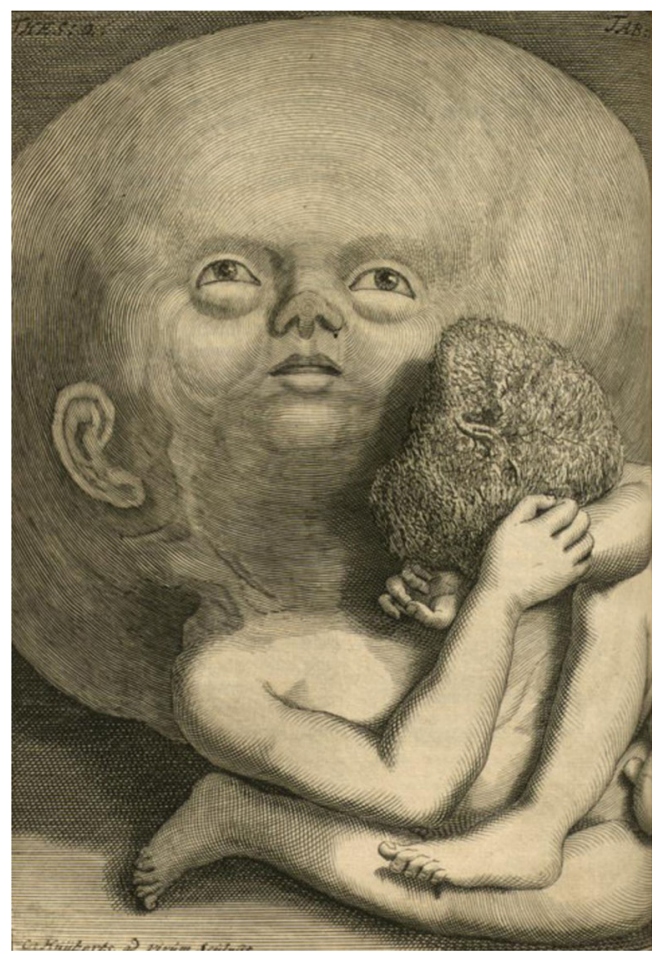

Fig. 1 and cover figure Infant with hydrocephalus engraved by Cornelis Huyberts for Frederik Ruysch's Thesaurus Anatomicus, 1701

concluded that puncturing the brain to drain the fluid would only make the condition worse [10]. The last two decades of the nineteenth century provided the first attempts of effective surgical treatment; in 1881, Carl Wernicke tried to drain

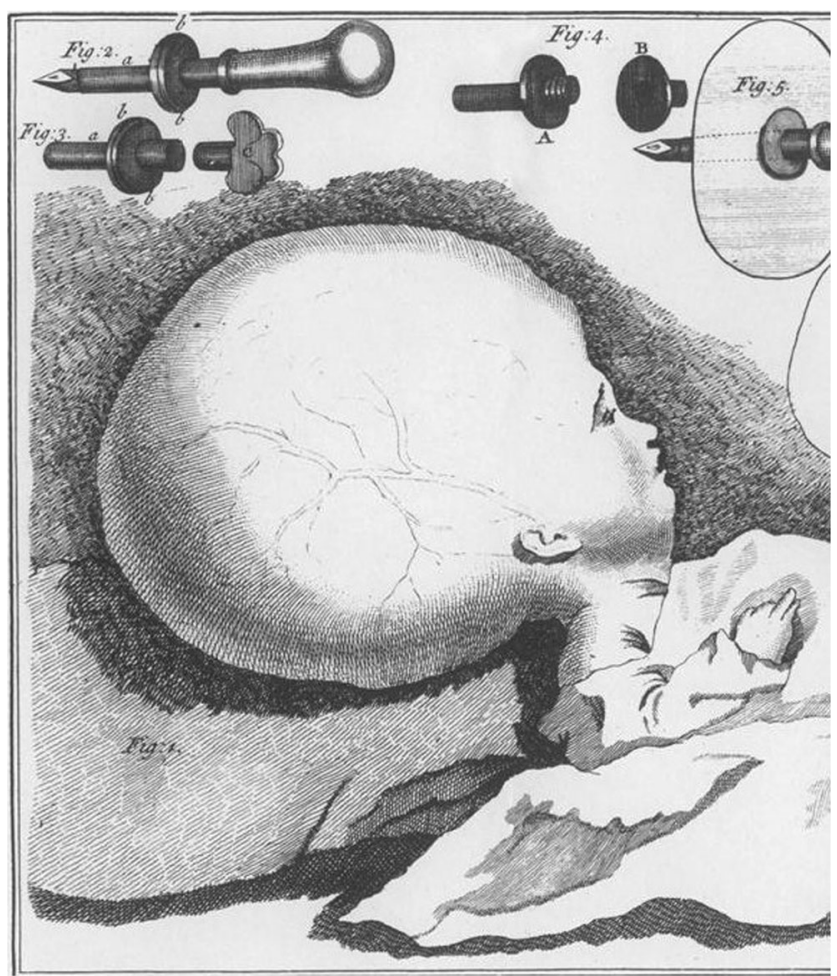

Fig. 2 Child with hydrocephalus from title page of Le Cat's treastise

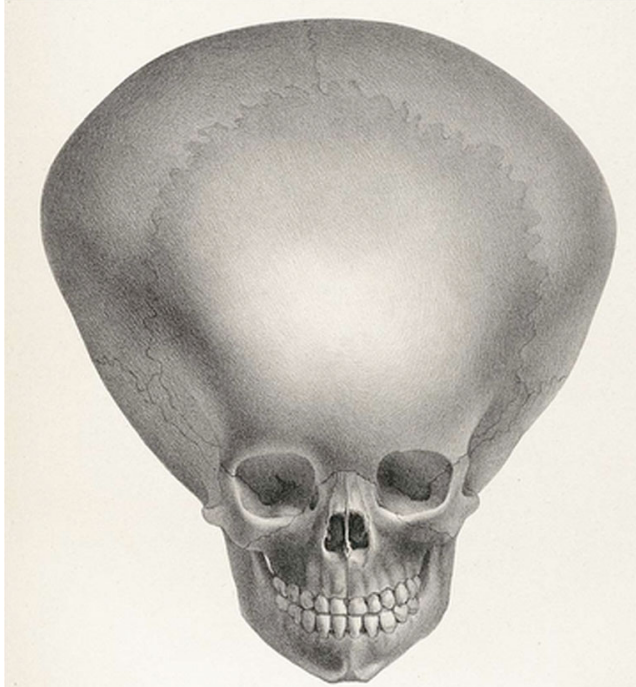

Fig. 3 Postmortem drawing of the skull from a patient with severe hydrocephalus. Taken from Joseph Vimont's Traite de Phrenology humaine et compare (Paris: J.B. Bailliere, 1832-35)

cerebrospinal fluid by performing ventricular punctures. In 1891, Heinrich Quincke attempted to drain CSF by performing serial lumbar punctures; then 2 years later in 1893, Jan Mikulicz-Radecki successfully inserted the first permanent ventriculo-subarachnoid-subgaleal shunt [1].

In 1898, William Cheyne reinvestigated the surgical treatment for hydrocephalus; his work with G. A. Sutherland focused on decreasing brain distension by connecting the ventricles to the subdural/subarachnoid space instead of draining the fluid outside of the skull thus preventing further complications such as infections. Their method used catgut sutures introduced earlier by Joseph Lister [11].

The story of hydrocephalus continues toward the twentieth century when the founder of modern neurosurgery, Harvey Cushing, made some of the greatest contributions to the treatment of hydrocephalus; he was the first to note that the choroid plexus was the main source of the excess cerebrospinal fluid. Cushing suggested draining the fluid into the retroperitoneal space at the level of the fifth lumbar vertebra, thus

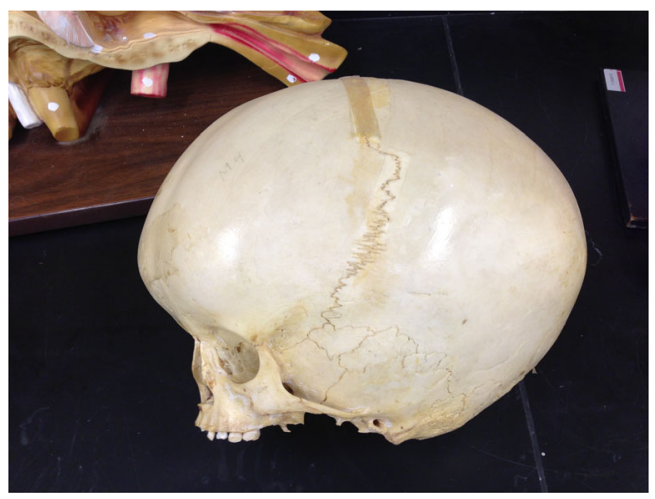

Fig. 4 Skull of a child with massive hydrocephalus 
providing an alternative to the unsatisfying method of draining the fluid into the subaponeurotic space of the scalp. He made the first documented attempt to create a shunt between the cisterna magna and the external jugular vein using a transplanted vein. This method was used in an infant with hydrocephalus, and the transplant was a cephalic vein donated by the patient's father $[12,13]$.

\section{Conclusions}

Today, hydrocephalus is routinely treated and with great success. Shunting childhood hydrocephalus is still the most common treatment, but endoscopic third ventriculostomy is being used more commonly. It is important to remember that in the recent past, hydrocephalus had a dismal outlook and most often met with mortality [14] (Fig. 4).

\section{References}

1. Aschoff A, Kremer P, Hashemi B (1999) The scientific history of hydrocephalus and its treatment. Neurosurg Rev 2:67-93

2. Turgut M (2009) Surgical scalpel used in the treatment of "infantile hydrocephalus" by Al Zahrawi (936-1013 A.D.). Childs Nerv Syst 25:1043-1044

3. Diemerbroeck I Trans, Salmon W (1694) The anatomy of human bodies; comprehending the most modern discoveries and curiosities in that art, to which is added a particular treatise of the small pox and measles together with several practical observations and experienced cures. London, p 208
4. Dymock E Hydrocephalus. University of Alberta. http://www. ualberta.ca/ illness/diseases/new_hydrocephalus.html Accessed on January 1, 2015

5. Kompanje EJ, Delwel EJ (2003) The first description of a device for repeated external ventricular drainage in the treatment of congenital hydrocephalus, invented in 1744 by Claude-Nicolas Le Cat. Pediatr Neurosurg 39:10-13

6. Le Cat Trans. Stack T (1751-1752) A new trocar for the puncture in the hydrocephalus, and for other evacuations, which are necessary to be made at different times. Philos Trans pp. 267-272

7. Friend J (1699) A letter from Mr. John Friend to Dr. Sloane, dated oxon. Jul. 26. concerning a hydrocephalus. Philos Trans pp. 318322

8. Tubbs RS, Loukas M, Shoja MM, Oakes WJ (2007) Matthew Baillie (1761-1823) and his early detailed descriptions of childhood hydrocephalus in the Morbid Anatomy. J Neurosurg 107:338-341, 4 Suppl Pediatrics

9. Goodrich JT (2010) Richard Bright (1789-1858) and his contributions to the understanding of hydrocephalus. Childs Nerv Syst 26: 593-594

10. Mian A, Shoja MM, Watanabe K, Rozzelle C, Loukas M, Tubbs RS (2013) Robert Liston (1794-1847): surgical anatomist and resurrectionist with an interest in hydrocephalus. Childs Nerv Syst 29:1-4

11. Watson CC, Griessenauer CJ, Loukas M, Blount JP, Tubbs RS (2013) William Watson Cheyne (1852-1932): a life in medicine and his innovative surgical treatment of congenital hydrocephalus. Childs Nerv Syst 29:1961-1965

12. Pendleton C, Zaidi HA, Jallo G, Cohen-Gadol AA, QuiñonesHinojosa A (2010) Harvey Cushing's use of a transplanted human vein to treat hydrocephalus in an infant in the early 1900s. J Neurosurg Pediatrics 5:423-427

13. Tubbs RS, Vahedi P, Loukas M, Cohen-Gadol AA (2011) Harvey Cushing's experience with treating childhood hydrocephalus: in his own words. Childs Nerv Syst 27:995-999

14. Lifshutz J, Johnson WD (2001) History of hydrocephalus and its treatments. Neurosurg Focus 11 (2): Article 1 